\title{
Influence of alternating current on corrosion behavior of X100 steel in Golmud soil simulated solution with different $\mathbf{p H}$
}

\author{
Jinlin Yang, Min Zhu*, Zhongping Le, Baozhu Zhao, Jun Ma, Yongfeng Yuan, Shaoyi Guo \\ School of Mechanical Engineering \& Automation, Zhejiang Sci-Tech University, Hangzhou 310018, \\ China \\ "E-mail: zmii666@126.com
}

doi: $10.20964 / 2020.10 .28$

Received: 6 May 2020 / Accepted: 22 July 2020 / Published: 10 August 2020

\begin{abstract}
The alternating current (AC) corrosion behavior of X100 steel was studied in Golmud soil simulated solution with different $\mathrm{pH}$ using electrochemical measurement, immersion test and surface analysis technology. The results show that $\mathrm{AC}$ interference and $\mathrm{pH}$ can collectively affect the corrosion behavior of the steel. The applied AC weakens the oxygen depolarization, enhances the hydrogen evolution reaction, and promotes the corrosion of the steel. The corrosion form of the steel evolves from non-uniform general corrosion to localized corrosion as $i_{A C}$ increases. Under the same interference of $i_{\mathrm{AC}}$, the corrosion rate of the steel first decreases and then increases with increasing the $\mathrm{pH}$ value. The difference in the characteristics of corrosion products can affect the corrosion resistance of the steel to a certain extent. When AC is applied, a great number of cracks existing in the corrosion products of sample under the condition of $\mathrm{pH}=7$ result in the severe corrosion. In contrast, the compactness corrosion product is conducive to protect the steel substrate tested at $\mathrm{pH}$ of 9 .
\end{abstract}

Keywords: Corrosion behavior; AC interference; X100; pH

\section{$\underline{\text { FULL TEXT }}$}

(C) 2020 The Authors. Published by ESG (www.electrochemsci.org). This article is an open access article distributed under the terms and conditions of the Creative Commons Attribution license (http://creativecommons.org/licenses/by/4.0/). 